Abbreviated Key Title: Sch J Econ Bus Manag

ISSN 2348-8875 (Print) | ISSN 2348-5302 (Online)

Journal homepage: https://saspublishers.com

\title{
Effect of COVID-19 on Teso Sub-Region Community in Eastern Uganda
}

Mutya Tomasi ${ }^{*}$, Se Kee Hong, Okodan Akwap, Kabi Ibrahim, Achom Santa, Joseph Omara, Orokode Joseph Jones

Kumi University, Uganda

DOI: $10.36347 /$ sjebm.2021.v08i01.004

| Received: 13.01.2021 | Accepted: 24.01.2021 | Published: 28.01.2021

*Corresponding author: Mutya Tomasi

\section{Abstract}

Original Research Article

The study aimed to achieve two main objectives. First, it sought to assess the effect of COVID-19 on the social wellbeing of people of Teso sub-region. Secondly, it sought to assess the effect of COVID-19 on the economic wellbeing of people in Teso sub-region. The study further sought to make recommendations on some of the practical ways that can enable the people of Teso to deal with COVID-19 and to survive in an era now globally known as the "new normal." The research design was a descriptive cross-sectional study among community members in three representative districts of Teso, namely Soroti, Katakwi and Kumi. Information from members of the community was collected using a closed-ended questionnaire comprising statements regarding the social and economic wellbeing of the people of Teso. The information was later descriptively presented as frequency and percentage. Additionally, an interview guide was used to collect data from members of District, Sub-county or Division Task Forces on COVID-19 in the three districts. The target population for this study was members of the Teso sub-region community. The sample size for this study was 150 respondents drawn from local communities for quantitative data and 26 members of task forces on COVID-19. A simplified quantitative analysis was used to capture three elements from quantitative data: mean range, response mode and interpretation. The study found that there was a very high awareness about COVID-19 and its symptoms in Teso. It also revealed a depressing trend arising from the impact of COVID-19 on the economy of Teso. Businesspeople were most affected adversely in economic terms.

Keywords: COVID-19, Social, Economic.

Copyright $\odot 2021$ The Author(s): This is an open-access article distributed under the terms of the Creative Commons Attribution 4.0 International License (CC BY-NC 4.0) which permits unrestricted use, distribution, and reproduction in any medium for non-commercial use provided the original author and source are credited.

\section{INTRODUCTION}

From around the end of 2019, the world has been faced with the deadly coronavirus, which seems to be here to stay for a long period. Therefore, in line with Kumi University's vision and mission, this study was generally intended to assess the effect of COVID-19, the disease caused by the coronavirus, on the Teso subregion community in Eastern Uganda. The first case of COVID-19 infection was confirmed in Uganda on March 21, 2020. According to the Ministry of Health (2020), the confirmed case was a 36-year-old Ugandan male who arrived in the country from Dubai on March 21. But even before that date, the government of Uganda had moved swiftly to announce a partial lockdown in the country on March 18. This was followed in quick succession by an announcement of a total lockdown of the country on March 30. That was the defining time communities and community participation became crucial in demonstrating how Ugandans could support official efforts to contain the spread of Covid-19 in the country. One of the key developments in those early days was the establishment of an entity known as the District Task Force (DTF) on COVID-19, which was mandated to spearhead the response to the Covid-19 threat at the community level. Every district in Teso has a DTF. There are also task forces at the Sub-county or Division level.

Meanwhile, in April Soroti Regional Referral Hospital set up a team of 39 staff to manage COVID-19 in the Teso sub-region. The team comprised 12 doctors, 16 nurses, five clinicians, two pharmacists, and three laboratory technicians. These are some of the concerted efforts that were put in place to control and manage the COVID-19 situation in Teso. This study recognises these efforts while focusing on the core subject of how COVID-19 has had an effect on the social and economic wellbeing of the people of Teso sub-region community by August 3-11 this year. Thus, this study should be significant for stakeholders in the fight against COVID-19 in Teso. 


\section{METHODOLOGY \\ Research Design}

The research design was a descriptive crosssectional study among community members in three representative districts of Teso sub-region, namely Soroti, Katakwi and Kumi. According to McCombes [1], descriptive research aims to accurately and systematically describe a population, situation or a phenomenon and it is an appropriate choice when the research aims to identify characteristics, frequencies, trends and categories. The study was also crosssectional as it involved looking at data from the same population at one specific point in time [2]. The researchers recorded information that was present in a population, but they did not manipulate variables. This type of research describes characteristics that exist in a community, but does not determine cause-and-effect relationships between different variables [2].

For this study, the descriptive research design involved data collection using both quantitative and qualitative methods. This design enabled the study to obtain data using self-administered questionnaires (quantitative method), while the interviews provided data using the qualitative method. "Triangulation" is the term often used to describe research where two or more data collection methods are used [3]. Furthermore, the term "cross-sectional" is often used to describe research which focuses on what is happening at the present moment [2].

\section{Data Collection Methods}

Information from members of the community was collected using a closed-ended questionnaire comprising statements regarding the social and economic wellbeing of the people of Teso. The information was later descriptively presented as frequency and percentage. Additionally, an interview guide was used to collect data from members of District, Sub-county or Division Task Forces on COVID-19 in the three districts of Soroti, Katakwi and Kumi. The descriptive research design offered the best option to provide sufficient insight into the research objectives by describing as succinctly as possible the effect of COVID-19 on the Teso sub-region.

The inclusion criteria used were: 1) Questionnaire respondents must be members of the community; 2) Interview respondents must be members of the District/Division/Sub-county Task Force on COVID-19. A simple random sampling technique was employed to quantitatively gather data from members of the community. Purposive and convenience sampling techniques were used for the qualitative method of collecting data from interviews with members of the respective task forces on COVID-19. These members of the task forces on COVID-19 were purposely selected by the researchers. They were also conveniently available to the researchers, close at hand and easy to reach [4]. Once a clear category of respondents for interviewing is determined prior to the commencement of the data collection exercise, the convenience samples include whoever happens to be available at the precise time researchers are conducting a study [4]. Sakaran [5] further asserted that the convenience sampling research strategy refers to the collection of information from people who are conveniently available to provide it to researchers at any given time. Thus, respondents who were interviewed were there at their places of work when the researchers arrived for interviews.

\section{Target Population}

The target population for this study was members of the Teso sub-region community. According to djs research [6], a market research company based in the UK, the target population is the entire population or group that a researcher is interested in researching and analysing. However, the Kumi University research team identified Soroti District, Katakwi District and Kumi District as the three representative districts out of nine where the field research would be carried out. The findings of the study are generalised to the target population, which is the Teso sub-region.

\section{Sample Size}

The sample size for this study was 150 respondents drawn from local communities for quantitative data (50 each from Soroti, Katakwi and Kumi), and 26 members of task forces on COVID-19 for qualitative data (nine from Soroti, eight from Katakwi and nine from Kumi).

\section{Data Gathering Procedures}

The qualitative research approach was applied to members of the District/Division/Sub-county Task Force on COVID-19 in the selected districts to gain greater understanding of what is on the ground as far as the fight against Covid-19 is concerned. It means that data was obtained by use of an interview guide, while quantitative data was obtained by using a study questionnaire. After the administration of the questionnaires the researchers retrieved all questionnaires from the respondents immediately after they were filled. Subsequently, the retrieved questionnaires were carefully checked to ascertain if they had been completely filled out and the data collected from the completed ones were carefully organised, coded and entered into a computer and were presented in the form of tables using the Statistical Package for the Social Sciences (SPSS) software. The SPSS is widely used by various market researchers, health researchers, survey companies, government entities, education researchers, marketing organisations, data miners, and many more for the processing and analysing of survey data [7].

\section{Quantitative Data Analysis}

A simplified quantitative analysis was used to capture three elements from quantitative data: mean range, response mode and interpretation. An item 
Mutya Tomasi et al., Sch J Econ Bus Manag, Jan, 2021; 8(1): 26-38

analysis using the following mean range was employed to arrive at the mean of the individual indicators and interpretation:

\begin{tabular}{|l|l|l|}
\hline Mean Range & Response mode & Interpretation \\
\hline $1.00-1.75$ & Strongly disagree & Low \\
\hline $1.76-2.50$ & Disagree & Medium \\
\hline $2.51-3.25$ & Agree & High \\
\hline $3.26-400$ & Strongly agree & Very high \\
\hline
\end{tabular}

This four-point Likert scale does not allow for a neutral midpoint such as a "neither agree nor disagree" response. Values for the options start with "Strongly disagree" at 1 point to "Strongly agree" at 4 points. The researchers opted for it on the contention that with all the impact of Covid-19 on virtually everybody in Teso, respondents had to provide specific responses to the statements in the questionnaire. Hopper [8] argues that using a Likert scale offering people a neutral point allows them to move on without giving careful thought to some of the statements.

This is an important point to note because, as Jameson [9] noted, a Likert scale rating system is used in questionnaires and is designed to measure people's attitudes, opinions or perceptions. The scale used in this study makes interpretation of mean scores and ranking of indicators easy.

\section{Interviews for Qualitative Data}

Interviews were conducted with a total of 26 members of the respective task forces on COVID-19. The qualitative data was obtained in accordance with the research objectives [10]. This data bolstered data which was quantitatively acquired to strengthen the study's findings. An interview guide containing 10 structured questions was used to obtain data expressed in non-numerical terms. This qualitative research approach was applied to members of the District/Division/Sub-county COVID-19 Task Forces in the selected districts to gain greater understanding of the measures being applied on the ground in respect to war against COVID-19.

The structured interview process is a research method which ensures that each interview is offered with the same questions in the same order and this guarantees that answers can be reliably collected and that comparisons can be made with confidence between interviewees' responses [11]. In descriptive studies, structured interviews can be used as an appropriate means to identify general patterns [12]. Indeed, Mcleod [13] pointed out that such interviews do not normally deviate from the interview schedule or guide except to clarify the meaning of the question or to probe beyond the answers received.

\section{Qualitative Data Analysis}

Analysis of the interview transcripts was based on content. Saunders et al., [12] explain that since the features of qualitative data are diverse in nature, there is no standardised procedure for analysing such data. Nevertheless, they argue that it is possible to group such data into three main types of processes: summarising (condensation) of meanings; categorisation (grouping) of meanings; and structuring (ordering) of meanings using narrative. This study chose the last type of data analysis because the procedure is associated with structuring meanings through narrative and it relies on researchers' interpretation [12]. By using a simple method of thematic qualitative analysis, each interview transcript can be carefully analysed to identify any comparisons that could be made between the interviewees' responses [11].

\section{Duration of Study}

The study was done between the middle of July and the end of September through the conceptual, design and planning, data collection, data analysis, and report writing phases.

\section{RESULTS AND INTERPRETATIONS}

In this section, the researchers present results and interpretations of the data they collected.

Table-1: Demographic Profile of Interview

\begin{tabular}{|c|c|c|c|}
\hline \multicolumn{4}{|c|}{ Respondents } \\
\hline \multicolumn{2}{|c|}{ Category } & Frequency & Percentage $(\%)$ \\
\hline District & Kumi & 09 & 34.6 \\
\hline & Soroti & 09 & 34.6 \\
\hline & Katakwi & 08 & 30.8 \\
\hline & Total & 26 & 100.0 \\
\hline Gender & Male & 22 & 84.6 \\
\hline & Female & 04 & 15.4 \\
\hline & Total & 26 & 100.0 \\
\hline
\end{tabular}

Source: Primary data, 2020

Table-1 shows that more than three-quarters of the sampled interview respondents, 22 or $84.6 \%$ were male, while four or $15.4 \%$ were female. Purposive sampling and convenience sampling techniques were used to select nine respondents in Kumi, nine in Soroti and eight in Katakwi for interview. This means that the respondents were purposely selected because of their role in the District/Division/Sub-county Task Forces on COVID-19. They were available for the interviews. 
Table-2: Social Demographic Data of Interview Respondents

\begin{tabular}{|l|l|l|l|}
\hline & Category & Frequency & Percentage \\
\hline Age group & $26-35$ & 08 & 30.8 \\
\hline & $36-45$ & 08 & 30.8 \\
\hline & $46-55$ & 08 & 30.8 \\
\hline & 56 and above & 02 & 07.6 \\
\hline & Total & $\mathbf{2 6}$ & $\mathbf{1 0 0 . 0}$ \\
\hline & Tertiary Level & 26 & 100.0 \\
\hline & Total & $\mathbf{2 6}$ & $\mathbf{1 0 0 . 0}$ \\
\hline
\end{tabular}

Source: Primary data, 2020

Table-2 shows that the interview respondents were evenly distributed by the age groups $26-35,36-45$, and 46-55, with each group contributing eight people or $30.8 \%$ of all those who were interviewed. The table shows a very slim minority of two respondents in the age group 56 and above, representing 7.6\%. Further, the table shows that all of the interview respondents had attained tertiary level education, with some having obtained diplomas, while some had attained university degrees. This was significant for the researchers in the sense that the interviewees were able to clearly and authoritatively describe and explain many of the salient aspects of COVID-19.

Table-3: Demographic Profile of Community Respondents

\begin{tabular}{|l|l|l|l|}
\hline & Category & Frequency & Percentage (\%) \\
\hline District & Kumi & 50 & 33.3 \\
\hline & Soroti & 50 & 33.3 \\
\hline & Katakwi & 50 & 33.3 \\
\hline & Total & $\mathbf{1 5 0}$ & $\mathbf{1 0 0 . 0}$ \\
\hline Gender & Male & 80 & 53.3 \\
\hline & Female & 70 & 46.7 \\
\hline & Total & $\mathbf{1 5 0}$ & $\mathbf{1 0 0 . 0}$ \\
\hline
\end{tabular}

Source: Primary data, 2020

Table-3 shows that the total number of respondents who returned completed questionnaires was evenly distributed, with Kumi, Soroti and Katakwi each accounting for 50 respondents or $33.3 \%$. (Coincidentally, Soroti City is equidistant from Kumi Town and Katakwi Town. According to Wikipedia [14], Kumi is located approximately 54 kilometres, by road, southeast of Soroti, while Katakwi is located approximately 55 kilometres, by road, north of Soroti.)
More than half of the sampled respondents, 80 or $53.3 \%$ were male, making them the majority. Less than half of the respondents, 70 or $46.7 \%$ were female. The number of questionnaires the researchers distributed in the three districts was 160 , but 10 of them were either not returned or were incomplete, rendering them invalid for processing. The study questionnaire was divided into two: Section A, captured social demographic data, while Section B captured effect of COVID-19 on the social wellbeing and economic wellbeing of the people of Teso.

Table-4: Social Demographic Data of Community Respondents

\begin{tabular}{|l|l|l|l|}
\hline & Category & Frequency & Percentage (\%) \\
\hline Age group & $18-25$ & 23 & 15.3 \\
\hline & $26-35$ & 75 & 50.0 \\
\hline & $36-45$ & 34 & 22.7 \\
\hline & $46-55$ & 11 & 07.3 \\
\hline & 56 and above & 4 & 02.7 \\
\hline & Total & $\mathbf{1 5 0}$ & $\mathbf{1 0 0 . 0}$ \\
\hline Education Level & Primary Level & 13 & 08.8 \\
\hline & Secondary Level & 41 & 27.5 \\
\hline & Tertiary Level & 62 & 41.6 \\
\hline & Others & 34 & 23.1 \\
\hline & Total & $\mathbf{1 5 0}$ & $\mathbf{1 0 0 . 0}$ \\
\hline
\end{tabular}

Source: Primary data, 2020 
Mutya Tomasi et al., Sch J Econ Bus Manag, Jan, 2021; 8(1): 26-38

Table-4 shows that 23 respondents or $15.3 \%$ were in the age group 18-25, while half of the respondents, 75 or $50 \%$ were in the age group 26-35. This means that nearly two-thirds of the respondents, 98 or $65.3 \%$ were in the two age groups, suggesting that the researchers interacted with mainly youthful people. This was statistically significant in the sense that the youth are the future of the Teso sub-region; whatever factor has as a negative or positive effect on their lives may also have a corresponding effect on the future of the sub-region. The age group 36-45 constituted 34 or $22.7 \%$ of the respondents, while the age group 46-55 constituted 11 or $7.3 \%$ of the total number of respondents. There were only four people in the age group 56 and above and they accounted for just $2.7 \%$ of the total number of questionnaire respondents.

In terms of education, the majority of respondents, 62 or $41.6 \%$ had a tertiary level education. Those with secondary education were 41 or $27.5 \%$, while 13 or $8.7 \%$ had primary education. Interestingly, 34 or $23.1 \%$ of the respondents were assisted to tick "others" on the questionnaire because they did not complete primary education. This category of people was included in the study because the aim of the study was to find out how COVID-19 had affected the people of Teso at the grassroots level, where there are still some people who have had no formal education.

Table-5: Effect of COVID-19 on the Social Wellbeing of the People of Teso Item Analysis

\begin{tabular}{|l|l|l|l|l|}
\hline Social wellbeing indicators & Mean & Interpretation & \% & Rank \\
\hline I am aware of the COVID-19 disease & 3.71 & Very high & 73.3 & 1 \\
\hline I know the symptoms of COVID-19 & 3.47 & Very high & 54.0 & 2 \\
\hline Increased teenage pregnancy in my community & 3.30 & Very high & 53.3 & 3 \\
\hline I know what to do in case I get symptoms of COVID-19 & 3.29 & Very high & 44.7 & 4 \\
\hline After the COVID-19 outbreak I feel more stressed & 3.18 & High & 42.7 & 5 \\
\hline I am worried about other diseases & 3.17 & High & 46.7 & 6 \\
\hline COVID-19 has increased gender based violence in my area & 3.12 & High & 43.3 & 7 \\
\hline I missed an important family event & 3.05 & High & 33.3 & 8 \\
\hline COVID-19 has helped me identify personal strengths & 2.99 & High & 52.0 & 9 \\
\hline COVID-19 has created spiritual change in my community & 2.95 & High & 39.3 & 10 \\
\hline I do regular physical exercises at home & 2.89 & High & 43.6 & 11 \\
\hline I guide my children at home & 2.83 & High & 48.0 & 12 \\
\hline It has made parenting better & 2.78 & High & 32.0 & 13 \\
\hline Strengthened my relations with others & 2.51 & High & 32.0 & 14 \\
\hline My children are studying at home & 2.51 & High & 36.7 & 15 \\
\hline I am worried about my mental health & 2.49 & Medium & 29.3 & 16 \\
\hline My children have access to internet & 1.89 & Medium & 46.7 & 17 \\
\hline Someone in the family was exposed to someone with Covid & 1.53 & Low & 56.0 & 18 \\
\hline Someone in the family had symptoms of COVID-19 & 1.50 & Low & 55.3 & 19 \\
\hline
\end{tabular}

Source: Primary data, 2020

\begin{tabular}{|l|l|l|}
\hline Mean Range & Response mode & Interpretation \\
\hline $1.00-1.75$ & Strongly disagree & Low \\
\hline $1.76-2.50$ & Disagree & Medium \\
\hline $2.51-3.25$ & Agree & High \\
\hline $3.26-400$ & Strongly agree & Very high \\
\hline
\end{tabular}

\section{'Very High' Awareness About COVID-19 and Its Symptoms}

Table-5 shows that the top four indicators received a "very high" interpretation meaning that the respondents "strongly agreed" with the statements in the questionnaire. "I am aware of the COVID-19 disease" ranks number one with a mean score of 3.71 or 73.3 percent. "I know the symptoms of COVID19 "ranks number two with a mean score of 3.47 or 54\%. "COVID-19 has increased teenage pregnancy in my area" ranks number three with a mean score of 3.30 or $53.3 \%$ and "I know what to do in case I get symptoms of COVID-19" received a mean score of 3.29 or $44.7 \%$. The "very high" interpretation of these indicators clearly suggests that by August 3, 2020 when the researchers started collecting data, the awareness level in Teso sub-region about COVID-19 was quite high. Indeed, the study found that the majority of community respondents sampled in the districts of Sorori, Katakwi and Kumi had sufficient information about the disease and its symptoms. The study found that this had a very significant implication for understanding how the central and local governments responded to the COVID-19 outbreak in Teso subregion.

Interviews with members of the task forces on COVID-19 in Soroti, Katakwi and Kumi revealed that various communication efforts were made to try to mitigate the challenges that the households in the Teso area faced socially and economically. For example, the task forces in these districts were sending 
comprehensive reports to the National Task Force on Covid-19. It is these reports from the ground that informed the government to make decisions on how to prevent and control the spread of COVID-19 in Uganda. The local authorities used radio mainly. Every week they were on local radio stations such as Voice of Teso, Teso Broadcasting Services, Etop Radio, and Caritas in Soroti, Continental FM in Kumi and Joshua FM in Katakwi. Mainly, they were messaging and counselling people to adhere to the Ministry of Health's standard operating procedures (SOPs). The study found that district officials had used radio extensively to sensitise people to wear masks and to report to local authorities anybody with symptoms of COVID-19.

In all of the districts visited, the researchers found that telephone contacts had been given to the community members to call in case of any COVID-19 related emergencies. Furthermore, the study found that local authorities went out of their way to urge people to help other community members in one way or the other. For example, parents were urged to take parenting responsibilities seriously and educate their children at home on mostly how to abstain from sex and to follow the Ministry of Health guidelines on how to stay safe and prevent the spread of Covid-19 pandemic. That is how community people got to know what to do in case they noticed anyone who showed signs and symptoms of COVID-19. The study found that this sensitisation was an on-going exercise. Local authorities were continuing to tell people to observe social distancing and washing hands with soap as regularly as possible. They were also repeatedly urging people: "If you have signs and symptoms consistent with COVID-19 seek medical help."

\section{'High' Stress Levels and Gender Based Violence}

Table-5 also shows that the next 11 social wellbeing indicators received a "high interpretation" meaning that respondents "agreed" with the questionnaire statements. The indicator, "After the COVID-19 outbreak I feel more stressed" was ranked fifth with a mean score of 3.18 or $42.7 \%$. This was followed by the indicator, "I am worried about other diseases" which was ranked sixth with a mean of 3.17 or $46.7 \%$. At number seven was, "COVID-19 has increased gender based violence in my community" with a score of 3.12 or $43.3 \%$. This was followed at number eight by the indicator, "I have missed an important family event" with a mean of 3.05 or $33.3 \%$.

The "high" interpretation of the four indicators above agrees with the big concerns expressed by the interview respondents as they talked about the many ways COVID-19 had affected people socially. According to a respondent, one major way Covid-19 had affected households in Soroti District was like this: "We witnessed instances of poor relations among household members, tending to domestic violence. Also, some of the persons released from the quarantine centre were rejected at their homes, so we had to bring them back to the centre. The issue of stigma became a reality in households. We had to use a psychosocial team to counsel people on stigmatisation."

In Kumi, a respondent stated: "School children being at home meant that families had to control their children. For those who failed to control their children, the children ended up pregnant." Another respondent in Kumi said: "This COVID-19 situation has basically increased the gender based violence in the community and an increase in teenage pregnancies."

In Katakwi, a respondent lamented that, "Every resource was now channelled to COVID-19 at the expense of other issues. For example, other diseases appeared to be ignored, like diabetes, HIV/Aids, among others. For instance, people could not easily travel to access their drugs. Government resources became overstretched. Vehicles were all for COVID-19. Teenage pregnancy between March and June reached 179. The defilement cases before March were just four cases, but after June there were 30 cases. The level of sexual activity rose very high."

The study found a great deal of concern regarding the matter of gender based violence. This matter was highlighted by virtually all the interview respondents. For example, in Kumi, a respondent said that, "One social aspect of COVID-19 was that we received more cases of gender based violence. It was high in the district. It was terrible. People had no finances to manage their domestic responsibilities. This could result in domestic violence."

\section{'High' Hope in the Face of Vicious Pandemic}

In Table-5, the study further shows that the seven social wellbeing indicators that were ranked number 9-15 with a "high" interpretation because respondents "agreed" with the statements, revealed a ray of hope amidst all the gloomy effect of COVID-19 on the social lifestyles of the people of Teso. The indicator, "COVID-19 has helped me identify personal strengths" was ranked ninth with a mean score of 2.99 or $52 \%$. This was followed at number 10 by the indicator, "COVID-19 has created spiritual change in my community" with a mean score of 2.95 or $39.3 \%$. At number 11 was the indicator, "I do regular physical exercises at home" with a score of 2.98 or $43.6 \%$. "I guide my children at home" was ranked number 12 with a score of 2.83 or $48 \%$. Number 13, "COVID-19 has made parenting better" had 2.78 or $32 \%$. Number 14 "COVID-19 has strengthened my relationships with others" also got 2.51 or $32 \%$. The last indicator in the "high" interpretation category, "My children are studying at home" had a score of 2.51 or $36.7 \%$.

The study found a similar ray of hope among the members of the District/Division/Sub-county Task Force. Generally, they expressed agreement that the 
Mutya Tomasi et al., Sch J Econ Bus Manag, Jan, 2021; 8(1): 26-38

dark cloud of COVID-19 had a silver lining. In Soroti, a respondent said: "We learnt a lot of lessons from COVID-19. For instance, disaster planning had not been taken very seriously before the pandemic and yet it is now critical at this time. The districts and central government should therefore plan for disasters and allocate adequate resources to counter such challenges." Another one added: "We had a number of radio stations to hold talk shows. Some radio owners were willing to give free airtime on COVID- 19 talk shows. World Vision, Teso Initiative for Peace and other NGOs are an opportunity to us."

In Kumi, a respondent said: “One opportunity was good commitment and team work for the District Task Force. For us to contain the first seven positive cases there was high commitment and team work among members. Another opportunity was that there was enough manpower to help us reach communities to get to people to know what Covid-19 is and how to control it."

In Katakwi, a respondent said: "The level of hygiene among community members has greatly increased. Hygiene-related diseases have decreased. This is attributed to the hand washing campaign to prevent spread of COVID-19. Vigilance and community mobilisation increased."

\section{Disagreement with Statements}

Nevertheless, Table- 5 shows that the next two indicators, "I am worried about my mental health" with a mean score of 2.49 or $29.3 \%$, and "My children have access to internet" with a mean score of 1.89 or $46.7 \%$ were rated "medium" because the respondents "disagreed" with those statements. The study did not find any concrete evidence why many people were not worried about their mental health. Yet Uganda has less than 50 psychiatrists for more than 40 million people [15]. But the study found that in Teso internet usage is low as many learners lack computers at home. Some rely on the available internet cafes to access digital information.
Also in Table-5 the indicator, "Someone in the family had symptoms of COVID-19" was ranked second last with a mean score of 1.53. At the very bottom of the table was the indicator, "Someone in the family was exposed to someone with COVID-19" with a mean score of 1.50. These two indicators were interpreted as "low" because respondents "strongly disagreed" with the statements. The study found no concrete empirical evidence about this strong disagreement beyond the fact that at the time data collection commenced on August 3 there were only a few confirmed COVID-19 cases in Teso that were successfully managed at Soroti Regional Referral Hospital. In that case, the study concluded that it was probable most of the respondents had not yet experienced the reality of COVID-19 in their local communities, much less in their families.

Soroti Regional Referral Hospital received its first COVID-19 patients on Monday, May 25. The Independent [16], reported that the patients included three women and one girl. They were among the first contacts of a businessman from Bukedea District who had tested positive for COVID-19 the previous week and was taken to Mbale Regional Referral Hospital for treatment. The group was quarantined at Atutur Seed Secondary School in Kumi District before testing positive. These first four patients caused a great deal of fear and panic in Kumi and Soroti. Ojore [17] reported in New Vision of May 27 that doctors in Soroti Hospital were in a dilemma as patients were secretly escaping from their wards following the admission of the first COVID-19 patients from Kumi. He reported that though the isolation ward was fenced off far from the other wards, the tension was high and uncontrollable. Similarly, fear gripped many health workers and members of the community in Kumi as they tried to come to terms with the shocking news of the first four COVID-19 cases in the Teso area. This panic was justified because a few days later COVID-19 struck Teso again. The Independent of June 2, 2020, reported that seven more people tested positive to COVID-19 at Soroti Referral Hospital, bringing the total number to 11.

Table-6: Effect of COVID-19 on the Economic Wellbeing of the People of Teso Item Analysis
\begin{tabular}{|l|l|l|c|c|}
\hline Economic wellbeing indicators & Mean & Interpretation & $\%$ & Rank \\
\hline I have experienced financial difficulties & 3.14 & High & 29.5 & 1 \\
\hline I was worried our food would run out & 3.03 & High & 37.3 & 2 \\
\hline I couldn't afford to eat a variety of food & 3.01 & High & 36.7 & 3 \\
\hline My eating habits have changed & 2.98 & High & 37.3 & 4 \\
\hline My family income has changed & 2.91 & High & 36.0 & 5 \\
\hline I had difficulty getting food & 2.91 & High & 38.0 & 6 \\
\hline I was worried about retaining my job & 2.66 & High & 30.7 & 7 \\
\hline I paid rent for the last three months & 2.42 & Medium & 29.3 & 8 \\
\hline I lost my job & 2.30 & Medium & 36.7 & 9 \\
\hline I am currently working from home & 2.23 & Medium & 32.7 & 10 \\
\hline Family and friends supported me & 2.17 & Medium & 37.6 & 11 \\
\hline My salary was cut & 2.10 & Medium & 42.0 & 12 \\
\hline I got relief food & 1.61 & Low & 62.7 & 13 \\
\hline
\end{tabular}


Mutya Tomasi et al., Sch J Econ Bus Manag, Jan, 2021; 8(1): 26-38

\begin{tabular}{|l|l|l|}
\hline Mean Range & Response mode & Interpretation \\
\hline $1.00-1.75$ & Strongly disagree & Low \\
\hline $1.76-2.50$ & Disagree & Medium \\
\hline $2.51-3.25$ & Agree & High \\
\hline $3.26-400$ & Strongly agree & Very high \\
\hline
\end{tabular}

Table-6 shows that the top seven indicators received a "high" interpretation, meaning that the respondents "agreed" with the questionnaire statements. The indicator ranked number one, "I have experienced financial difficulties" has a mean score of 3.14 representing 29.5 percent. The second one, "I was worried our food would run out" has a score of 3.03 or $37.3 \%$, and the third, "I couldn't afford to eat a variety of food" got a mean score of 3.01 or $36.7 \%$. "My eating habits have changed" takes the fourth slot with a mean score of 2.98, followed by, "My family income has changed" with a score of 2.91; "I had difficulty getting food" is placed at number 6 with a score of 2.91 or 38 per cent followed in seventh position by the indicator, "I am worried about retaining my job" with a mean score of 2.66 or $30.7 \%$.

\section{Depressing Trend from Impact of COVID-19}

The economic wellbeing indicators ranked number 1-7 in Table-6 reveal a depressing "high" trend arising from the impact of COVID-19 on the economy of Teso. The "high" interpretation of these economic indicators highlights a sudden turn of events for worse for many households as COVID-19 disrupted economies and livelihoods of households across the board. Even the basic things that had catered for the physiological needs of people, such as food, suddenly became problematic. Clearly, with the COVID-19 pandemic lurking ominously everywhere, business activity in Teso was affected badly; people could not access the big weekly markets such as Arapai in Soroti, Ocor imongin in Katakwi and Odelo in Kumi. Cattle markets had been the lifeline of many people in Teso. Their closure affected household income badly. For example, many people who got loans from microfinance institutions were unable to service them due to the situation brought by COVID-19. And some people who were staying in rented apartments found themselves unceremoniously thrown out by their landlords. For some, the businesses and workplaces which had been food baskets suddenly got affected.

The interview respondents also agreed across the board that COVID-19 unleashed sudden and unexpected economic pains on the people of Teso. In Kumi one respondent told a researcher: "We realised that there were some cases of malnutrition. The local economy was low and people could not feed themselves, leading to malnutrition." In Soroti, another one said: "COVID-19 has also impacted on the rural communities negatively in the marketing of their products in that they now sell them at giveaway prices just to get some money for meeting their basic needs." And in Katakwi District, "most businesses collapsed due to the transport restrictions and the lockdown."

\section{From Depressing 'High' to Mellow 'Medium'}

The economic wellbeing indicators ranked 812 are also largely work-related. Their mean scores fall between 2.0 and 2.45 , meaning that the respondents "disagreed" with the statements on the questionnaire. The indicator ranked number 8 , "I paid rent for the last three months" had a mean score of 2.42 or $29.3 \%$. The ninth indicator, "I lost my job" received a mean score of 2.30 or $36.7 \%$. This was followed in tenth position by the indicator, "I am currently working at home" with a score of 2.23 or $32.7 \%$. The indicator ranked number 11, "Family and friends supported me" received a score of 2.17 or $37.6 \%$, while indicator number 12 , the last one in this cluster, "My salary was cut" had a mean score of 2.10 or $42 \%$.

The interpretation of these five indicators reveals a change from the depressing "high" trend of the first seven indicators to a rather mellow "medium" elucidation for numbers 8-12. Part of the explanation here is that the study sought views of some of the people who lived in communities where they were engaged in the informal sector. Some did not have to worry about losing their jobs. Some resided in their own homes in the community, so they did not have to worry about paying rent. Even for some of those who were employed, there was no arrangement for them to continue carrying out their work at home. There was a curfew and there were restrictions on public transport and use of private vehicles, including the boda bodas most commonly available to community people. This meant that many people simply stayed home day and night. It is also probable that lack of support from family and friends was a contributing factor to the rise in gender based violence, defilement and other negative behaviours the study was informed about.

At the bottom of Table- 6 is the indicator, "I got relief food" with a "low" mean score of 1.61. One of the mitigation measures the government announced after the outbreak of COVID-19 was the programme for food distribution to citizens. But the programme was not well implemented and many people who should have got the relief food of posho and beans did not get anything. Indeed, the official editorial opinion of Saturday Monitor newspaper of July 18, 2020 noted that the government's communication on matters of COVID-19 had largely been problematic. The newspaper stated: "The government's communication has left citizens at crossroads. Apart from distributing food rations once, government has not made clear pronouncements to save people from an uncertain future amid job loss and salary cuts. This is likely to invite criminality since such citizens may want to strive to live yet the means are curtailed." 


\section{QUALITATIVE DATA ANALYSIS AND INTERPRETATION}

The structured interviews focused on the following six main themes: How COVID-19 affected the households in the district socially; how COVID-19 affected the households in the district economically; the challenges District/Division/Sub-county task forces faced; the opportunities task force members encountered; what task force members did to mitigate the challenges the households faced; and how community members participated in the fight against COVID-19
How COVID-19 Affected Households Socially

The study found that the effects of COVID-19 were twice or three times more than the number of respondents the researchers interacted with. For example, In Katakwi, the COVID-19 period registered an increase in land conflicts. This is because most of the urban dwellers had lost jobs and therefore had no other alternative but to come back to the villages that they had abandoned. Also, gender based violence increased. The major reason given was that women and men had not been used to staying at home all the time for a long time, so simple mistakes made them angry leading to violence. Indeed, the Action Aid Shelter registered a rise in people seeking services such as psychosocial support, mediations and legal counselling as shown in the Table below:

Disaggregation of registered Action Aid clients by sex and age category
\begin{tabular}{|l|l|l|l|l|l|l|}
\hline Category & $\mathbf{0 - 1 4}$ & $\mathbf{1 5 - 1 7}$ & $\mathbf{1 8 - 3 0}$ & $\mathbf{3 1 - 4 9}$ & $\mathbf{5 0 +}$ & Total \\
\hline Females & 8 & 24 & 129 & 146 & 5 & 312 \\
\hline Males & 0 & 1 & 10 & 17 & 6 & 34 \\
\hline TOTAL & 8 & 25 & 139 & 163 & 11 & 346 \\
\hline
\end{tabular}

In Kumi District, the uptake of health services had been affected and this had led to the rise of certain infections. Also, conducting sensitisation meetings in the district had become very difficult as gatherings had been banned. Further, there was over-consumption of alcohol among some individuals, leading to diseases like liver cirrhosis. Cases of suicide were also reported.

From Soroti, COVID-19 the researchers were told that COVID-19 had affected rural and urban households positively as well as negatively. The urban dwellers had been positively affected socially when they moved from town to villages to do agriculture which was productive to them. But negatively, people had been affected in that they had lost jobs, domestic violence has escalated, family separation was on the rise and about 400 prostitutes had to come out openly to agitate for food from the district authorities. They even threatened to continue romping with the truck drivers (a group considered high risk in terms of virus spread) if their needs were not met. Domestic violence, underage pregnancies and other social problems had also come out strongly.

In all the districts, the ban on social gatherings meant that interactions among family members became restricted. There was even stigmatisation of some families that received visitors from other areas where COVID-19 cases had been. Worship in public places was restricted. Some people were arrested for sneaking to pray in churches and other places. There was a general sense of confusion. In fact in Kumi, a respondent said that there were also incidences of reported cases of mental illnesses and "even managers of COVID-19 were confused on where to start."
Apart from the high rates of drunkenness, drug abuse had reportedly increased in Teso. And apart from some of the school children who were at home getting pregnant, child labour became rampant. Then there was the matter of idle youths stealing chicken, cattle, and other properties. The confusion arising from the ban on gatherings also saw some families getting divided as some members were locked up in other places far from their families. Some families living in urban areas had to shift to villages. School children who were not accessing learning materials became confused because the schools had remained closed for an extended period.

But all was not lost. The study found that COVID-19 had actually united people in some areas. The sense of togetherness that had emerged improved the relationships between some people, including the relations between husbands and their family members. It was even observed that people had become more responsible. They were staying home and engaging in agriculture. In fact, in Soroti and Kumi people were expecting bumper harvests in crops such as maize, sweet potatoes, sorghum, groundnuts and green grams, known in the Ateso language as "ecoroko". There was also bonding between some parents and their children. Parents who had not been used to staying with children for a long time came to understand the characters of their children and it seemed that the increase in domestic violence was due to failure to handle home responsibilities.

\section{How COVID-19 Affected Households Economically}

From the interviews the study established that in all the districts, the people most affected adversely in economic terms included businesspeople. Operators of shops, boda bodas, salons, cattle markets, bars and other 
businesses which were closed incurred huge losses. Indeed, if it was not for agriculture that remained resilient, the economic outlook would have been bleaker. Overall, the lockdown affected people negatively across the board. People were not going to work. People were not paid. There was loss of livelihoods everywhere. People's businesses closed. People were losing jobs. COVID-19 was biting some sectors more severely than others. Taxi and bus operators, weekly market vendors, boda boda motorcycle operators, salon owners, artisans and others were some of the most severely affected sectors.

Private school teachers were among the nonbusiness people most economically affected. In Kumi, a respondent said: "Private school teachers stopped to be paid because they had been relying on tuition fees. These dried up because of closure of schools. Also, people used to take produce to markets near and far, but all this stopped. People used to do a lot of business in the marketplace. Shops and cattle markets were closed, except shops selling food items. With the closure of schools it meant that those who had been supplying food and other materials to these institutions lost a lot of money. Some, however, receive half pay from owners of schools."

In Katakwi, the study found that a combination of factors worsened the economic situation there. Markets were not open. Most businesses collapsed due to the ban on transport and the lockdown. Drought from January to May ruined agriculture and foot-and-mouth disease also broke out.

Nevertheless, on a positive note, Soroti and Kumi had weather that was favourable at the same time Covid-19 broke out. Respondents there said optimistically that bumper harvests were expected in the districts. One said: "This means people will be able to sell some of their crops." Also on a positive note, low attendance was registered in out-patient departments at health points in the Teso area because people were washing hands. Personal and domestic hygiene improved in communities. Hence, fewer diarrhoeal diseases were reported in health points. Even TB reduced in the communities because people were wearing masks. This was respiratory hygiene and it improved. By being healthy the people of Teso focused on economic activities. They also realised the need to have savings in their families to prepare for eventualities such as COVID-19.

\section{Challenges Task Force Members Faced}

There was remarkable similarity of views regarding challenges faced by task force members. Overwhelmingly, inadequate funding was cited as a top challenge in all the districts. In Soroti, a member said: "We faced challenges of inability to move because of lack of funds for transport. The district is large, but calls were coming in from everywhere. Another challenge was that we were even responding to false information from people just telling lies. When we started to get money, we realised that it was just a flat rate. Soroti District, with a Municipality that is autonomous and a referral hospital, was given the same amount of money as a small district such as Kalaki in Kaberamaido subregion. Shs $165 \mathrm{~m}$ was given for three months, April to June. So the money was very inadequate for us" Another one said: "One of the major challenges we have faced is money, specifically an inadequate budget. We started with nothing. There was no fuel to respond to calls from community members. Soroti has a big population. There was lack of personal protective equipment. We were going to see people, even without masks. Also, the notion of suspected COVID-19 patients feeding themselves in quarantine could not work. We had to mobilise food donations from NGOs and others to feed suspects." Others at the Division level made remarks such as, "The fuel was insufficient" or, "Reaching out to the community was not easy due to inadequate transport since the Division has no vehicles and motor cycles."

In Kumi it was the same lament. A member said: "As part of the foot soldiers at grass root level, the local councils (LCs) and village health teams (VHTs) were not budgeted for as far as transport, meals and airtime were concerned. They used their own resources to do government work. They are not given any airtime even for reporting suspected cases of COVID-19, so they had to buy it on their own. This has affected the implementation of government programmes." Another one narrated: "The major challenge was finances. Secondly, we had a challenge of false alerts from the community members. They would say that a person is from Kenya, yet the person is not from there. We wasted fuel. We wanted every sub-county to have a vehicle but we lacked them. Also, there was a time the district lacked so many things, even a quarantine centre. Later, the district gazetted a quarantine centre in Atutur Seed Secondary School. The greatest challenge came when we got seven confirmed cases of Covid-19. Our challenge was how to transport them to the Regional Referral Hospital in Soroti. We took some good time to get them to Soroti." Also in Katakwi finances were not enough to help in the facilitation and enforcement of the SOPs.

Katakwi members particularly cited the difficulty of controlling the taking of the popular local millet brew known as "ajon" because there was a lot of hide-and-seek between the police and some community people. Although some people stopped drinking others continued. They started drinking in the swamps and bushes. They would dig a hole and put a pot in it. Then they would use a long tube for sucking the brew while perched high on tree branches to avoid detection. 
Similarly, many people in Soroti and Kumi were not taking COVID-19 seriously. In many cases, social distancing has never been adhered to. The reason was that people lived in communities that socialised a lot by participating in drinking in groups, either in bars selling beer or in places where the local millet brew "ajon" was sold. The situation was made very challenging by the people in these drinking joints because even when they were dispersed, they ended up going to drink in the forests and swamps, thereby putting themselves at risk of contracting COVID-19.

\section{Opportunities Task Force Members Encountered}

One general area of opportunity the task forces encountered was that they developed partnerships with other stakeholders in the fight against COVID-19. Again, there was remarkable agreement on opportunities that specifically arose as a result of the task forces partnering with NGOs and private sector players. Some opportunities came from the business communities in the districts as well as from religious leaders and NGOs such as World Vision, who donated the necessary items to vulnerable persons in the districts. These items included fuel, food and beddings. The food was particularly critical for feeding suspected COVID-19 patients who were placed in quarantine centres. The beddings that came in the form of blankets and mattresses mainly were equally critical. Other items included clothing, jerry cans for hand washing, sanitisers, and liquid soap.

These donations eased the work of task force members. The opportunity of regular washing of hands started to be practiced as a habit. It helped reduce the incidence of communicable diseases like diarrhoea. As a matter of fact, the level of hygiene among community members greatly increased while hygiene related diseases decreased. Other opportunities came in the form of increased vigilance of people in some communities. This helped a lot in the fight against the pandemic. Indeed, community members became sensitive to other people coming into their communities because they did not want the disease coming to their communities from outside. Other opportunities came in the form of districts putting up gazetted quarantine centres. As a result, the centres set up psychosocial teams that helped in the fight against COVID-19. The training of health workers was also an advantage; it increased preparedness to handle epidemics. In terms of agriculture, the interviews revealed a high participation of men, women and children in subsistence farming. People were staying at home and they took to growing crops for food.

\section{What Task Force Members Did to Mitigate Challenges}

The study found that to mitigate all the social and economic challenges of COVID-19, members of the various District/Division/Sub-county teams did a tremendous job carrying out radio talk shows on the FM stations in Kumi, Katakwi and Soroti about COVID-19. Even on radio talk shows the members were sensitising people on other salient aspects of the day such as gender based violence. Again, partnership with entities such as World Vision, Action Aid and Rhite-E, (an NGO which handles reproductive health in the Teso sub-region) bore fruits. Notably, domestic and personal hygiene improved. The partnerships used the WASH (water, sanitation and hygiene) approach, which focused on latrine coverage and domestic water for drinking and hygiene. The sanitation aspect of these mitigation measures was that Kumi District reported that latrine coverage had improved from $68 \%$ to $89 \%$ and hand washing moved from $65 \%$ to $75 \%$ from fiscal year $2018 / 19$ to $2019 / 20$. So, COVID had both negatives and positives.

The study further found that the element of mass sensitisation of people living in communities was particularly crucial in the early days of the outbreak of the pandemic in the Teso sub-region. This is because many people lived in fear and uncertainty. It was, therefore, commendable that the task force members did all they could to try to sensitise community people. Educating people in communities remained an on-going activity. Task force members continued to sensitise people to observe the Ministry of Health guidelines and to distribute masks to people in communities.

Apart from continuously creating awareness about social issues such as domestic violence, the mass sensitisation campaigns in the districts at the time of data collection in early August focused on reminding people in the communities to keep on observing the various standard operating procedures already spelled out by the government. At that time, distribution of food to the vulnerable persons such as boda-boda operators was an on-going mitigation activity. And this was done majorly by identifying the most affected persons and families. Equally, the members of District/Division/Sub-county Task Force were emphasising the use of masks in public places.

\section{How Community Members Participated in the Fight against COVID-19}

No narrative on the effects of COVID-19 on the Teso sub-region community would be robustly complete without bringing in the crucial aspect of the participation of community members themselves in the fight against the pandemic. The Encyclopedia of Quality of Life and Well-Being Research [18] defined community participation as the direct involvement of citizens or citizen groups potentially affected by or interested in a decision or action. This study found that throughout the districts of Soroti, Katakwi and Kumi, community contribution in the fight against COVID-19 in Teso sub-Region was truly great, especially during the early days. Early in the epidemic, the community participated in making calls and alerts to the local authorities, especially the office of the District Health 
Officer. The calls mainly were reporting people who had travelled and returned to their communities. People also were making alerts or calls about presence of people coming into the community from outside. They were also reporting people who had flu-like conditions. Furthermore, they participated through the enforcement of standard operating procedures by reporting those who were not observing Ministry of Health guidelines. For example, people alerted authorities about those who were violating social distancing rules by sitting close to one another in drinking places and in video halls or dancing in disco halls.

Community members also participated in the fight against Covid-19 largely by reporting to local authorities people who were suspected to be COVID-19 cases. Community members were very useful by being vigilant. If community members happened to see a new person within their community they would report to the division or sub-county task force for response. Even those who had travelled to other places, especially high risk places such as Kenya were reported. So, community members were vigilant and reporting suspected cases of Covid-19. The members also participated greatly in identification of those who might have caught a fever. Members of village health teams were trained to identify persons with symptoms related to COVID-19. Further, community members played a big role in dissemination of educational materials for case definitions, signs and symptoms of COVID-19. They also responded on provision of hand washing facilities at home and information about how to wash hands. Some donated food. Some were involved in the sensitisation of members of the community. The village health teams and LC officials delivered information to the people on prevention and control of COVID-19. Thus, people in the communities started making inquiries about COVID-19 from taskforce members.

\section{CONCLUSIONS}

From the results and interpretations of data, the researchers make the following conclusions: First, nearly two-thirds of the community respondents of this study, 98 or $65 \%$ were in age bracket $18-35$. This means that the research gauged the opinions of the youth, who rightly should be seen as the future of Teso sub-region. Therefore, the negative and positive effect of COVID19 on this youthful segment of the population of Teso may have a corresponding effect on their future social and economic wellbeing, depending on how the problem COVID-19 will be solved.

Second, by August 3, 2020 when the researchers started collecting data, the awareness level in Teso sub-region about COVID-19 was very high. Indeed, the study found that the majority of community respondents sampled in the districts of Sorori, Katakwi and Kumi had sufficient information about the disease and its symptoms, largely due to mass sensitisation programmes the task forces carried out. The study found that this had a very significant implication for understanding how the central and local governments responded to the COVID-19 outbreak.

Third, the study shows that many of the questionnaire respondents agreed that after the outbreak of COVID-19 they felt more stressed. They also indicated that COVID-19 had increased gender based violence in their communities. Similarly, the interview respondents painted a bleak picture of the unexpected and rapid ways COVID-19 had negatively affected people socially in the districts. They said that poor relations among household members increased domestic violence.

Fourth, the study however revealed that there was a ray of hope amidst all the gloomy effects of COVID-19 on the social lifestyles of the people of Teso. People identified personal strengths, they experienced spiritual change in their communities, they did regular physical exercises, and they guided their children at home. This showed a lot of positive thinking in times of uncertainty. The study found a similar ray of hope among the members of the task forces on COVID19

Fifth, the greatest drawback in the fight against COVID-19 was inadequate funding. The Shs165 million each district received was nothing more than a drop in the ocean. This money could not cover even cover basic activities such as transport and much less the core functions of task forces such as surveillance, welfare, coordination for meetings and allowances of task force members, risk communication and training, psycho-social support, and clinical care and management.

\section{RECOMMENDATIONS}

The researchers made the following recommendations, objective by objective:

\section{Objective 1: Effect of COVID-19 on the Social Wellbeing of the People of Teso}

- The Task Force should work in collaboration with other District organs to strengthen social protection measures to mitigate the escalating problems associated with early pregnancies, early marriages, defilement and child labour.

- The Task Force should continue sensitising the communities on the WASH (water, sanitation and hygiene) programmes to improve the basic hygiene and sanitation practices such as hand washing in the communities.

- The Task Force should work in collaboration with other District organs to mitigate issues of gender based violence in the communities. 
Mutya Tomasi et al., Sch J Econ Bus Manag, Jan, 2021; 8(1): 26-38

Objective 2: Effect of COVID-19 on the Economic Wellbeing of the People of Teso

- The Task Force should strive to strengthen the agricultural sector to ensure food security and commercial production of cash crops.

- Government should consider providing stimulus packages not only to Small and Medium Enterprises (SMEs), but also to Micro Enterprises at the grass roots level.

- The Task Force should encourage members of the community to embrace Information Technology practices that promote electronic transactions to minimise the health risks arising from crowds gathering for physical cash transactions.

\section{ACKNOWLEDGEMENT}

In a very special way, the researchers wish to recognise the contribution of $\mathrm{Mr}$. Joseph Elungat, Assistant Lecturer in the Department of Information Technology at Kumi University. He gets the special thanks for assisting the researchers in the critical process of analysing the study's data.

\section{REFERENCES}

1. McCombes S. Descriptive research. 2020. Available on: https://www.scribbr.com/methodology. Retrieved on September 19, 2020.

2. Cherry F. Stubborn Particulars of Social Psychology: Essays on the Research Process. Routledge; 2019 May 24.

3. Heale R. Understanding triangulation in research. 2013. Available on: https://www.ebn.bmj.com. Retrieved on September 25, 2020.

4. Amin ME. Social science research: Conception, methodology and analysis. Kampala: Makerere University Printery. 2005.

5. Sakaran U. Research methods for business: A skill building approach. Hoboken, New Jersey, USA: John Wiley and Sons. 2003.

6. djs research. Target population. 2020. Available on: https://www.djsresearch.com. Retrieved on: September 15, 2020.

7. Foley B. What is SPSS and how does it benefit survey data analysis? 2018. Available on: https://www.surveygizmo.com. Retrieved on September 16, 2020.

8. Hopper J. Why you need 4-point scales. 2016. Available on: https://www.verstaresearch.com. Retrieved on: September 16, 2020.

9. Jameson S. Likert scale in social science. 2020. Available on: https://www.britannica.com. Retrieved on: September 15, 2020.

10. Hewlett DMA. Community participation in local decision-making in protected areas: The case of the New Forest National Park, Hampshire, England. A thesis submitted in partial fulfillment of the requirements of Bournemouth University for PhD degree. 2010.

11. Bryant L. Structured interviews. Anglo-European School, Ingatestone, Essex, UK. 2012. Available on:

https://www.historylearningsite.co.uk/structured_i nterviews.htm. Retrieved on April 28, 2019.

12. Saunders M, Lewis P, Thornhill A. Research methods for business students. (Fifth ed.). New York: Prentice Hill. 2009.

13. McLeod. The interview research method. 2014. Available: https://www.simplypsychology.org. Retrieved on September 18, 2020.

14. Wikipedia. Location of Kumi District/Location of Katakwi District. 2020. Available on: https://www.en.m.wikipedia.org. Retrieved on: September 22, 2020.

15. Nantume G. How peer pressure, drug abuse is ruining women's lives. 2020. Feature article in Daily Monitor of September 23, 2020. Available on: https://www.monitor.co.ug. Retrieved on September 24, 2020.

16. The Independent. Soroti Hospital receives first COVID-19 patients. 2020. Available on: https://www.independent.co.ug. Retrieved on September 22, 2020.

17. Ojore G. Patients flee Soroti Hospital after admission of 4 corona cases. 2020. Article in the New Vision newspaper of May 27, 2020. Available on: https://www.newvision.co.ug. Retrieved on: September 22, 2020.

18. Encyclopedia of Quality of Life and Well-Being Research. Community participation. 2014. Available on: https://www.link.springer. Retrieved on August 25, 2020. 